\title{
Electrical potential difference and absorption of water, sodium, and potassium by the terminal ileum of ileostomy patients
}

\author{
J. PRADO p. de MORAES-FILHO, C. SALAS-COLL, LAURIE BLENDIS, AND \\ C. J. EDMONDS
}

\begin{abstract}
From the MRC Department of Gastroenterology, Central Middlesex Hospital, and MRC Department of Clinical Research, University College Hospital Medical School, London
\end{abstract}

SUMMARY Measurements of electrical potential difference (pd) and of absorption by a dialysis method were carried out in the terminal ileum of patients with an ileostomy. The pd measured with saline in the lumen and at a few centimetres within the stoma averaged $9.2 \mathrm{mV}$, lumen negatively charged. The pd values were similar whether the ileostomy had been recently or long established. The pd rose considerably when glucose was added to the luminal solution, the maximum effect being attained with a concentration of $40 \mathrm{mmol} / \mathrm{l}$. With a saline bicarbonate solution ( $\mathrm{Na} 145$ or $140 \mathrm{~m}$-equiv/1, K 5, or $10 \mathrm{~m}$-equiv/l) in the dialysis tube, considerable absorption of fluid and sodium was demonstrable with little change in sodium concentration. Potassium secretion occurred with the lower, and absorption with the higher, concentration. The final luminal potassium concentration reached was consistent with a passive distribution between blood and lumen.

Relatively simple methods are now available to measure the transmucosal electrical potential difference and electrolyte transport characteristics of the rectum (Archampong and Edmonds, 1972; Edmonds, 1971). Since the procedures are atraumatic and can be done in the course of routine examinations, it is possible to make repeated observations and so study changes produced by hormones, drugs, or pathological processes (Edmonds, 1971; Rask-Madsen, and Jensen, 1973; Edmonds and Pilcher, 1973). Similar methods should be suitable for study of the epithelium of the terminal ileum in a patient with an ileostomy and the object of the present work was to examine the feasibility of the procedures in this situation.

\section{Methods}

Eleven patients (seven males, four females, 24-54 years), were studied. They had all been treated for ulcerative colitis by total colectomy and had normally functioning ileostomies. The studies were done at between two weeks and six years after formation of the ileostomy. In all the ileum appeared healthy and was functioning satisfactorily.

Received for publication 16 August 1974.
POTENTIAL DIFFERENCE MEASUREMENTS

The measurements were made at intervals during a period of follow up of the patients. The system used is illustrated in figure 1. The intraluminal bridge was formed of a rubber catheter (diameter $0.2 \mathrm{~cm}$ ) completely filled with the solution under study and connected by a three-way tap to a syringe which acted as a reservoir for the solution and to another syringe which contained a calomel electrode in a solution of $3 \mathrm{~mol} / \mathrm{l} \mathrm{KCl}$. The reference electrode was constructed of perspex (lucite) and contained a silver-silver chloride junction in saline-agar. It was placed on the outer part of the right thigh, the skin having been previously injected with saline to abolish the skin pd (Archampong and Edmonds, 1972). The gut was rinsed thoroughly with the solution under study and about $5 \mathrm{ml}$ of the solution from the reservoir was introduced through the electrode tube before pd measurements to ensure electrical contact with the intestinal epithelium. The asymmetry pd of the system (about $15 \mathrm{mV}$ ) was checked before and after the measurements and the observed pd corrected for the asymmetry to obtain the true transmucosal potential difference. Only stable electrode pairs were employed in these studies. A portable batteryoperated high-input impedance millivoltmeter was used. The input impedance of the millivoltmeter was 


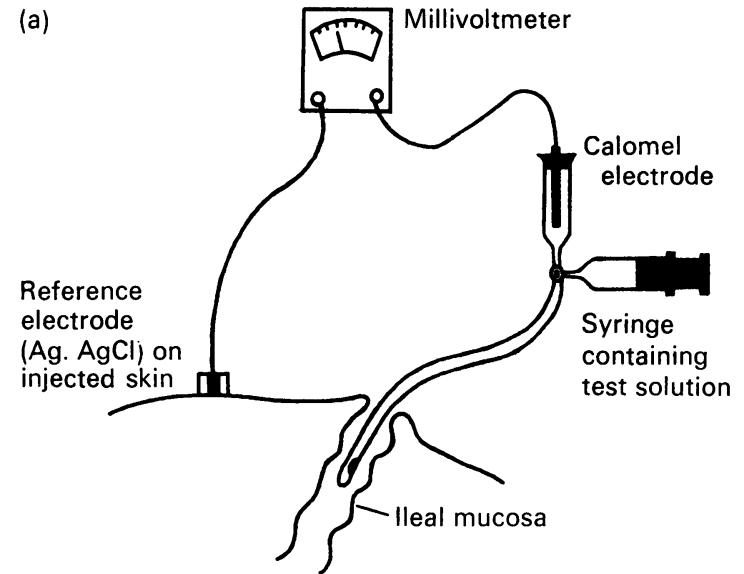

(b)

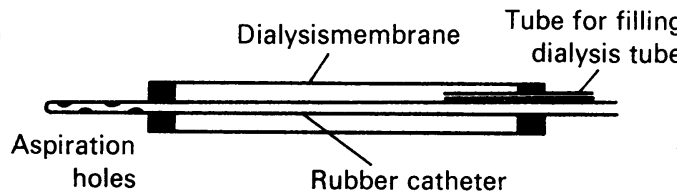

Fig 1 Diagrammatic representation of (a) the method of measurement of the transmucosal pd in a patient with an ileostomy and (b) the dialysis tube used for measuring water and ionic absorption and secretion.

about $10^{10} \Omega$ and its calibration was checked against a Vibron electrometer (EIL 33b).

\section{ABSORPTION STUDIES}

The dialysis method (Edmonds, 1971) which employs a tube of dialysis membrane (Visking tubing 8/32) mounted on a rubber catheter (diameter $0.2 \mathrm{~cm}$ ) was modified in two ways for the present work. First a fine polythene tube was included for filling the dialysis chamber. Secondly, the central rubber cannula extended beyond the chamber and aspiration of ileal contents and constant suction was applied during the experiment. The dialysis chamber had a diameter of $0.5 \mathrm{~cm}$ and length of $7 \mathrm{~cm}$ and was placed in the ileum at a position from 3 to about $10 \mathrm{~cm}$ from the stoma for 30 minutes. The tubes were weighed before and after experiments to measure fluid absorption, the tube first being wiped clean of any adherent mucus or other fluid. The tube was carried between weighings in a small, impermeable plastic container. Preliminary trials showed that by this procedure weight loss from evaporation was reduced to a negligible amount. The total weight of tube with fluid was about 7.5 to $8 \mathrm{~g}$ and the weight loss was from 0.17 to $0.49 \mathrm{~g}$. Measurements were made to the nearest $\mathrm{mg}$ on a Mettler (Zürich) type $\mathrm{H} 16$ balance. The ileum was rinsed with about $20 \mathrm{ml}$ of test solution before each experiment and fluid was removed by gentle suction. Specimens or tubes contaminated with ileostomy effluent were discarded.

SOLUTIONS AND CHEMICAL METHODS

Perfusion solutions were freshly prepared before each experiment from stock solutions. All solutions used in the experiments (table I) were isotonic, mannitol being added in appropriate amounts when necessary. The osmolality was always confirmed before starting an experiment. Sodium and potassium were determined by flame photometry. The fluxes are expressed in terms of the surface area of the dialysis tube (total area $11.2 \mathrm{~cm}^{2}$ ) and calculated as previously described (Edmonds, 1971).

\begin{tabular}{|c|c|c|c|c|c|c|}
\hline \multirow[t]{2}{*}{ Solution Called } & & \multicolumn{5}{|c|}{ Composition } \\
\hline & & \multicolumn{2}{|c|}{$\begin{array}{l}N a \quad K \\
\text { (m-equiv/l) }\end{array}$} & \multicolumn{2}{|c|}{$\mathrm{HCO}_{3} \mathrm{Cl}$} & $\begin{array}{l}\text { Organic } \\
(\mathrm{mmol} / \mathrm{l})\end{array}$ \\
\hline Saline & I & 150 & - & - & 150 & - \\
\hline Saline-bicarbonate & $\begin{array}{l}\text { II } \\
\text { III }\end{array}$ & $\begin{array}{l}145 \\
140\end{array}$ & $\begin{array}{r}5 \\
10\end{array}$ & $\begin{array}{l}30 \\
30\end{array}$ & $\begin{array}{l}120 \\
120\end{array}$ & - \\
\hline Saline-glucose & IV & 130 & - & - & 130 & Glucose 40 \\
\hline Saline-mannitol & $\begin{array}{l}\text { V } \\
\text { Va }\end{array}$ & $\begin{array}{l}130 \\
120\end{array}$ & - & - & $\begin{array}{l}130 \\
120\end{array}$ & $\begin{array}{l}\text { Mannitol } 40 \\
\text { Mannitol } 60\end{array}$ \\
\hline Saline-choline & $\begin{array}{l}\text { VI } \\
\text { VII }\end{array}$ & $\begin{array}{r}130 \\
13\end{array}$ & - & - & $\begin{array}{l}150 \\
150\end{array}$ & $\begin{array}{l}\text { Choline } 20 \\
\text { Choline } 137\end{array}$ \\
\hline
\end{tabular}

Table I Composition of solutions used

Results

PD MEASUREMENTS

Some observations on the characteristics of the ileostomy pd were made when saline (solution I) or saline bicarbonate (solution II) was in the gut lumen. As observed by Fordtran, Rector, and Carter (1968), there was no significant difference between saline bicarbonate and saline and so saline was used in most experiments. The luminal side of the mucosal epithelium was found to be negatively charged with respect to the blood side and reversal of the pd was not observed in the present series of experiments. In six of our patients, the pd measured close to the ileostomy stoma was compared with that found when the probe was inserted deeply. At $3 \mathrm{~cm}$ from the stoma, the pd ranged from 8.6 to $18.3 \mathrm{mV}$, mean $14.3 \pm 0.8 \mathrm{mV}$ (SEM), and at $10 \mathrm{~cm}$ it ranged from 7.6 to $12.3 \mathrm{mV}$, mean $9.2 \pm 0.7 \mathrm{mV}$. The pd appeared therefore to be significantly increased close to the stoma (P $<0.001)$.

In five of the patients, the pd was measured repeatedly over a period of up to eight months. Relatively little variation was observed, the greatest being $\pm 12 \%$ around the mean value in one of the 
subjects. The time for which the ileostomy had been established also appeared to make little difference to the potential difference. In three of our patients measurements were done within four weeks of forming the ileostomy; they gave a mean of $8.5 \mathrm{mV}$ (range 7.6 to 9.1). This value is to be compared with that obtained from nine patients (including one of the three, first measured within four weeks of the ileostomy being formed) who had an ileostomy established for from six months to six years and which had a mean of $7.2 \mathrm{mV}$ (range 2.2 to $12.2 \mathrm{mV}$ ). Although the mean value was slightly lower in the long-established ileostomies than in the recentlyestablished group (and also than that found in the group of six patients quoted above), this was due to the inclusion of one patient (with an ileostomy established 10 months) who had a persistently low pd of less than $3 \mathrm{mV}$.

\section{EFFECT OF GLUCOSE AND SODIUM}

The measured pd was found to increase considerably when glucose was added to the luminal solution even though osmolality was kept constant (fig 2). The effect was reversed rapidly when the glucosecontaining solution was removed. Using luminal solutions containing glucose in increasing concentration, it was found that a concentration of 10 $\mathrm{mmol} / \mathrm{l}$ had very little effect and that a maximum effect was achieved with a concentration of about $\mathbf{4 0}$ $\mathrm{mmol} / \mathrm{l}$ (fig 2). The newly formed ileostomy (studied about three weeks postoperatively) behaved in the same way in respect to this action of glucose, as those which had been established for several months or longer. In the 11 subjects, in the presence of glucose (solution IV) the pd had a mean value of $18.7 \pm 3.4$ (SEM), while in the absence of glucose (solution V) it was $8 \cdot 3 \pm 2 \cdot 5$ (SEM).

No systematic study of the effect of luminal ions was made in the present investigation but some observations did indicate that the pd was affected by the luminal sodium concentration. Thus reducing the luminal sodium concentration from 130 (solution VI) to $13 \mathrm{mmol} / 1$ (solution VII), by substituting (a)

(b)

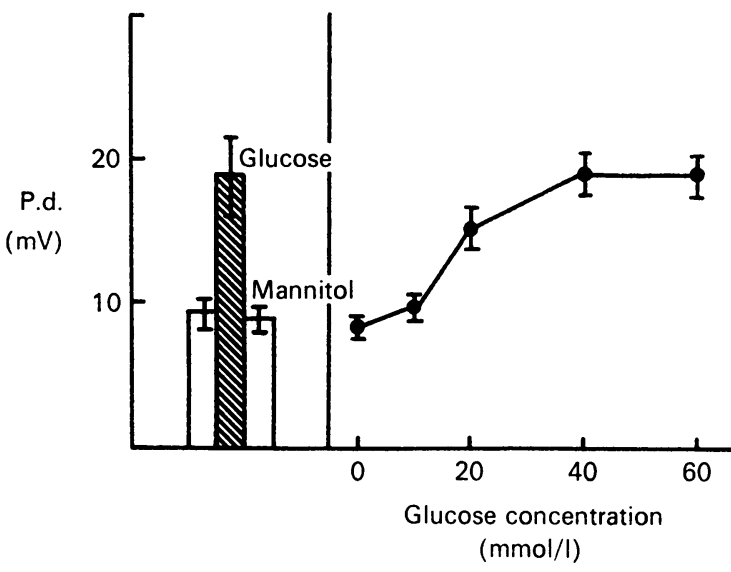

Fig 2 Effect of glucose on $p d(\bar{M} \pm S E M)$ measured in five of the patients: (a) comparison of pd when glucose replaced mannitol in a luminal solution (solutions $I V$ and $V)$, having sodium concentration $130 \mathrm{mmol} / \mathrm{l} ;(b)$ effect of replacing mannitol in solution $V a$ with progressively increasing amounts of glucose.

choline chloride so that chloride concentration remained unchanged, was consistently associated with a fall of pd which reversed when sodium was reintroduced. In five individuals in whom this was done, the pd with solution VI had a mean value of 9.4 (range 3.4 to 13.6$) \mathrm{mV}$ falling to $2 \cdot 1$ (range -3.4 to 6.8) $\mathrm{mV}$ when solution VII was in the lumen.

\section{ABSORPTION MEASUREMENTS}

When the saline bicarbonate (solution II) was in the dialysis tube no significant change in sodium concentration was observed during the 30 minutes' exposure (table II) although potassium concentration rose significantly $(P<0.01)$. The fluid weight always fell during the experiment by about 10 to $25 \%$ indicating that considerable absorption of fluid and sodium had taken place. Potassium, on the other hand, was secreted but only to a small extent when

\begin{tabular}{|c|c|c|c|c|c|c|c|}
\hline & \multicolumn{4}{|c|}{ Concentration Changes } & \multicolumn{3}{|c|}{ Absorption Secretion } \\
\hline & \multicolumn{2}{|c|}{ Sodium (m-equiv/l) } & \multicolumn{2}{|c|}{ Potassium (m-equiv/l) } & Sodium & Potassium & Water \\
\hline & Initial & Fina & Initial & Final & \multicolumn{2}{|c|}{ 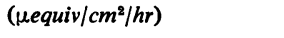 } & $\mathrm{ml} / \mathrm{cm}^{2} / \mathrm{hr}$ \\
\hline $\begin{array}{l}\text { Saline bicarbonate } \\
\text { Solution II }\end{array}$ & 145 & $\begin{array}{l}142 \\
\pm 2 \cdot 6\end{array}$ & 4.9 & $\begin{array}{r}6.0 \\
\pm 0.9\end{array}$ & $\begin{array}{r}+10.5 \\
\pm 3.6\end{array}$ & $\begin{array}{l}-0.032 \\
\pm 0.45\end{array}$ & $\begin{array}{l}+0.070 \\
\pm 0.018\end{array}$ \\
\hline $\begin{array}{l}\text { Saline bicarbonate } \\
\text { Solution III }\end{array}$ & 139 & $\begin{array}{l}138 \\
\pm 1 \cdot 4\end{array}$ & $10 \cdot 5$ & $\begin{array}{r}6.8 \\
\pm 0.2\end{array}$ & $\begin{array}{r}+12 \cdot 4 \\
\pm 4 \cdot 3\end{array}$ & $\begin{array}{l}+2 \cdot 02 \\
\pm 0 \cdot 37\end{array}$ & $\begin{array}{l}+0.081 \\
\pm 0.036\end{array}$ \\
\hline
\end{tabular}

Table II Absorption of water, sodium, and potassium from a dialysis chamber in the ileum observed in 14 studies in nine patients (mean $\pm S D$ )

Absorption + ve; secretion - ve 
the initial concentration was about 5 m-equiv/l. Measurements were also made when the dialysis tube contained potassium at a higher initial concentration (solution III). Again sodium concentration did not change significantly, although water and sodium absorptions were similar to those found with solution II. However, with the higher initial potassium concentration (about $10 \mathrm{~m}$-equiv/l) potassium was always absorbed and potassium concentration invariably fell $(\mathrm{P}<0.01)$ during the 30 minutes' exposure (table II).

In fig 3, the results obtained from a similar study on the rectum in four normal individuals using the saline bicarbonate in a diaysis tube are compared with those obtained from the ileostomy studies. There is a

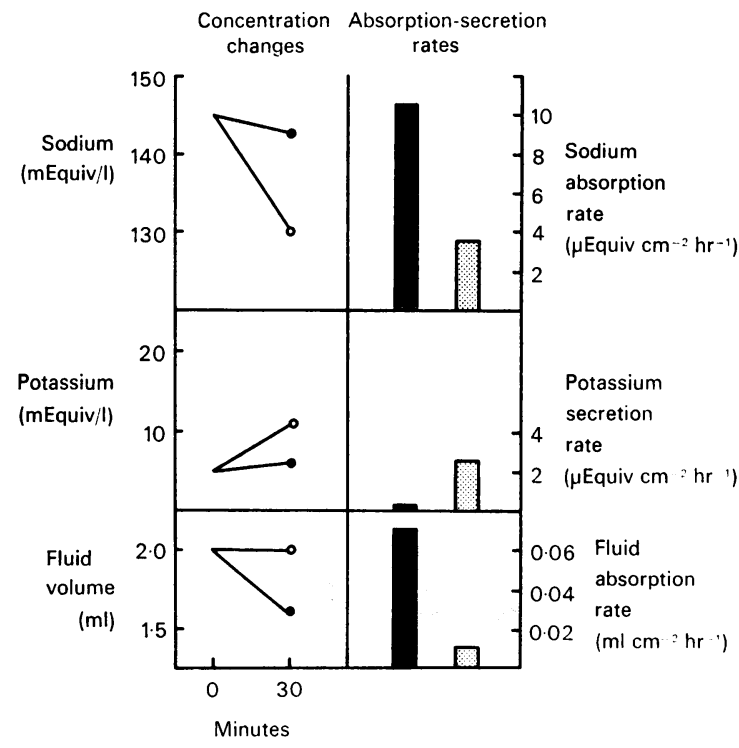

Fig 3 Absorption and secretion during a 30-minute period by the mucosa of ileum $(\bullet)$ and rectum $(O)$ measured by the dialysis method with saline bicarbonate (solution II) in the lumen. The results for the ileum were obtained from nine individuals with ileostomy and those for the rectum from four individuals (eight studies) with normal gut function.

clear difference in the behaviour of the two epithelia. In the rectum, there was an obvious fall in sodium concentration and rise in potassium concentration, but very little water absorption. The sodium absorption rate was lower in the rectum than in the ileum but the potassium secretion rate was several times greater. The pd in the rectum was considerably higher than in the terminal ileum averaging $37 \mathrm{mV}$ lumen negative.

\section{Discussion}

The reported results of ileal transmucosal pd measured with a balanced electrolyte solution in the lumen are surprisingly variable. Gustke, Whalen, Geenen, and Soergel (1967) found values as high as $17 \mathrm{mV}$ but the majority of observers (Fordtran et al, 1968; Sachar, Taylor, Saha, and Phillips, 1969; Turnberg, Bieberdorf, Morawski, and Fordtran, 1970) have reported values less than $10 \mathrm{mV}$ and frequently less than $5 \mathrm{mV}$. Our results showed that the pd within the first few centimetres inside the stoma was consistently greater than that observed more deeply, probably reflecting a modification in the ileal epithelium in this region due to the ileostomy itself. Most of the values obtained at $10 \mathrm{~cm}$ deep to the stoma were less than $10 \mathrm{mV}$ but they did tend to be on average greater than those found in most of the studies quoted above, though whether this represents a real difference or one simply due to differing methodology is uncertain at present. Individuals measured at intervals over several months showed good consistency and from our results it appears that the ileal pd alters little over the years after ileostomy has been established.

The effect of glucose in increasing the pd of the small intestine, both in vitro and in vivo, as well as the interaction of glucose and sodium absorption, has been described in many different species (Schultz and Curran, 1970). The changes of pd produced by glucose that we observed were of similar magnitude to those observed in normal individuals during ileal perfusion (Fordtran et al, 1968; Sachar et al, 1969). The effect of glucose was only evident when its luminal concentration exceeded $10 \mathrm{mmol} / 1$, that is, when it was higher than the blood level. In view of the interaction of glucose and sodium absorption, the pd rise might be accounted for by glucose stimulation of sodium absorption. There is, however, evidence that glucose does not increase sodium absorption in the ileum (Gustke et al, 1967; Fordtran et al, 1968) and so this explanation seems unlikely. At present the way in which the pd increase is produced remains uncertain.

The studies with the dialysis chamber showed that there was considerable absorption of water and sodium when saline bicarbonate was in the lumen. Since the blood side of the epithelium was positively charged, sodium was absorbed against the electrochemical gradient consistent with its active transport. Ileal perfusion studies have shown that ileal mucosa can absorb sodium against considerable concentration gradients (Fordtran et al, 1968), but in contrast to the rectum we observed only a slight fall in intraluminal sodium concentration. This was because water was also absorbed so that hypotonicity 
did not develop. Comparison with the absorption rate determined by perfusion of the ileum can be made by using the data of Fordtran et al (1968). They found that during perfusion of a $30 \mathrm{~cm}$ segment of ileum with a solution of sodium concentration 125 m-equiv/l, the absorption rate was about 6 $\mathrm{m}$-equiv $/ \mathrm{hr}$. Taking the ileal diameter as $3.5 \mathrm{~cm}$, the absorption rate based on an area calculation, the ileum being considered as a simple cylindrical tube, was $18 \mu$ equiv $\mathrm{hr} \mathrm{cm}^{2}$, a value a little less than twice that estimated by the dialysis method. Considering how different methods are and particularly that during perfusion the gut lumen is distended, with an effectively greater surface area, this difference in absorption rate by the two methods is not large. The discrepancy probably therefore depends on the difference in method rather than on a modification of epithelial function consequent on ileostomy.

In the colon, the reduction of luminal sodium concentration is accompanied by a rise of potassium concentration while in the ileum very little rise of potassium concentration was observed. Thus the average potassium concentration rose to only 6.0 m-equiv/l when the initial value was $5 \mathrm{~m}$-equiv/l and fell to $6.8 \mathrm{~m}$-equiv/1 when the initial value was 10 m-equiv/l. For a normal average plasma potassium concentration of $4.2 \mathrm{~m}$-equiv/ 1 and a transmucosal pd of $9.2 \mathrm{mV}$ and assuming a purely passive distribution of potassium across the epithelium, an intraluminal concentration of about $5.9 \mathrm{~m}$-equiv/1 would be expected. Thus our observed values are consistent with the conclusion of perfusion studies (Phillips and Summerskill, 1967; Turnberg, 1971) that potassium is passively distributed across the ileal mucosal layer.

In conclusion, it appears that the ileal mucosa beyond the first few centimetres of the stoma of an ileostomy behaves similarly to the ileum of the intact gut in regard to pd, water, sodium, and potassium transport. Relatively simple methods can be used to study the accessible part of the ileum after ileostomy, thus offering a useful means of examining the action of drugs and hormones and of testing the functional state of the ileal epithelium.

The work of Dr J. Prado p. de Moraes-Filho was done during tenure of a fellowship of the Fundacão de Amparo à Pesquisa do Estado de São Paulo, Brazil, and that of Dr C. Salas-Coll during tenure of a fellowship of CONICIT, Venezuela. We thank Sir Francis Avery Jones and Dr T. D. Kellock for allowing us to study their patients and Messrs G. D. Searle Co Ltd for the loan of a portable high-input impedance millivoltmeter.

\section{References}

Archampong, E. Q., and Edmonds, C. J. (1972). Effect of luminal ions on the transepithelial electrical potential difference of human rectum. Gut, 13, 559-565.

Edmonds, C. J. (1971). Absorption of sodium and water by human rectum measured by a dialysis method. Gut, 12, 356-362.

Edmonds, C. J., and Pilcher, D. (1973). Electrical potential difference and sodium and potassium fluxes across rectal mucosa in ulcerative colitis. Gut, 14, 784-789.

Fordtran, J. S., Rector, F. C., Jr., and Carter, N. W. (1968). The mechanisms of sodium absorption in the human small intestine. J. clin. Invest., 47, 884-900.

Gustke, R. F., Whalen, G. E., Geenen, J. E., and Soergel, K. H. (1967). Mucosal potential difference in the intact human small intestine. Gastroenterology, 52, 1134.

Phillips, S. F., and Summerskill, W. H. J. (1967). Water and electrolyte transport during maintenance of isotonicity in human jejunum and ileum. J. Lab. clin. Med., 70, 686-698

Rask-Madsen, J., and Brix Jensen, P. (1973). Electrolyte transport capacity and electrical potentials of the normal and the inflamed human rectum in vivo. Scand. J. Gastroent., 8, 169-175.

Sachar, D. B., Taylor, J. O., Saha, J. R., and Phillips, R. A. (1969). Intestinal transmural electric potential and its response to glucose in acute and convalescent cholera. Gastroenterology, 56, 512-521.

Schultz, S. G., and Curran, P. F. (1970). Coupled transport of sodium and organic solutes. Physiol. Rev., 50, 637-718.

Turnberg, L. A. (1971). Potassium transport in the human small bowel. Gut, 12, 811-818.

Turnberg, L. A., Bieberdorf, F. A., Morawski, S. G., and Fordtran, J. S. (1970). Interrelationships of chloride, bicarbonate, sodium, and hydrogen transport in the human ileum. J. clin. Invest., 49, 557-567. 